\title{
Orographic Signature on Extreme Precipitation of Short Durations
}

\author{
Francesco AVANZI AND CARlo De Michele \\ Department of Civil and Environmental Engineering, Politecnico di Milano, Milan, Italy \\ SALVATORE GABRIELE \\ Istituto di Ricerca per la Protezione Idrogeologica, Consiglio Nazionale delle Ricerche, Rende, Italy \\ ANTONIO GHEZZI AND RENZO Rosso \\ Department of Civil and Environmental Engineering, Politecnico di Milano, Milan, Italy
}

(Manuscript received 28 March 2014, in final form 20 August 2014)

\begin{abstract}
This paper investigates how atmospheric circulation and orography affect the spatial variability of extreme precipitation in terms of depth-duration-frequency (DDF) curve parameters. To this aim, the Italian territory was considered because it is characterized by a complex orography and different precipitation dynamics and regimes. A database of 1494 time series with more than 20 years of maximum annual precipitation data was collected for the durations of 1,3, 6, 12, and $24 \mathrm{~h}$. For each data series, the parameters of DDF curves were estimated using a statistical simple scale invariance model. Hence, the combined effect of orography and atmospheric fields on parameter variability was investigated considering the spatial distribution of the parameters and their relation with elevation. The vertically integrated atmospheric moisture flux $\mathbf{J}$ was used as a measurement of the principal direction of the vapor transport at a given location. The analysis highlights the variability of DDF parameters and quantiles according to orography and precipitation climatology. This is confirmed by the evaluation of $\mathbf{J}$ modal direction over the study area. The variability of DDF parameters with mere elevation shows that maxima at high elevations seem to be upper bounded and more variable than those at lower elevations. Moreover, the mean of maximum annual precipitation of unit duration decreases with elevation. This last phenomenon is defined as "reverse orographic effect" on extreme precipitation of short durations.
\end{abstract}

\section{Introduction}

Precipitation dynamics are the result of a complex set of interactions including fluid dynamics, thermodynamics, and microscale cloud processes (Roe 2005). Precipitation is usually considered to be either of stratiform or convective nature, or a mixture of the two. In many cases, convective and stratiform precipitations co-occur. An example is the case of convective cells embedded within stratiform precipitation (Houze 1997). The surface topography acts as a boundary for the atmospheric circulation. It plays a fundamental role in determining climate gradients on Earth (Roe 2005). The typical effect of orography on precipitation is the well-known orographic

Corresponding author address: Francesco Avanzi, Politecnico di Milano, Piazza Leonardo da Vinci 32, IT-20133 Milan, Italy.

E-mail: francesco.avanzi@mail.polimi.it lift consisting of the local enhancement of precipitation by means of moist air uplift operated by versants (Bonacina 1945; Sarker 1966; Alpert 1986; Barros and Kuligowski 1998; Smith et al. 2003; Smith and Barstad 2004; Roe 2005; Smith 2006; Rotunno and Houze 2007; Mott et al. 2014). This entails different dynamics between wind- and lee-ward slopes. Consequently, precipitation climatology at a site can be strongly influenced by orography, as observed, for example, by Viale and Nuñez (2011) in the Andes; Minder et al. (2008) in the Olympic Mountains, Washington State, United States; Anders et al. (2006) in the Himalayas; or Gheusi et al. (2002) and Gheusi and Stein (2003) in northwest Italy.

Extreme precipitation causes damage and high costs for modern societies (Salvadori et al. 2007). Recent cases include the June 2013 event in eastern Europe (Blöschl et al. 2013); the November 2011 flash flood in Genoa (Italy), with 19 fatalities (Silvestro et al. 2012); 
the August 2002 event in Germany, which caused \$15 billion (U.S. dollars) in total costs (Mueller 2003; Coumou and Rahmstorf 2012); and the November 1994 event in Piedmont (Italy), with 70 fatalities and roughly $\$ 12$ billion (U.S. dollars) in economic losses (Buzzi et al. 1998). Thus, the assessment of extreme precipitation magnitudes is a key issue in hydrology, also because of their predicted increase in the future as a response to climate change (Kunkel et al. 1999; Alpert et al. 2002).

The rarity of extreme precipitation is usually investigated by means of the so-called extreme value theory (von Mises 1923; Gumbel 1958; Koutsoyiannis 2004a,b; Salvadori et al. 2007; Kottegoda and Rosso 2008, and references therein) and is quantified through the concept of "return period" $T$ (Chow et al. 1988, 380-383). This is defined as the average time between two realizations of an event of given probability of exceedance (Salvadori et al. 2011). The calculation of the return period requires the identification of a suitable probability distribution for the variable of interest. An exhaustive literature review on this topic can be found in Kottegoda and Rosso (2008) and Salvadori et al. (2007). In this context, Jenkinson $(1955,1969)$ determined the asymptotic distribution of extreme values, that is, the so-called generalized extreme value (GEV) distribution, with cumulative distribution function equal to

$$
F(x)=e^{-[1-k / \alpha(x-\epsilon)]^{1 / k}} .
$$

This depends on three parameters, namely, $k$, $\epsilon$, and $\alpha$. These are the shape, location, and scale parameters, re-spectively (Kottegoda and Rosso 2008). The value of the shape parameter characterizes the type of asymptotic tail of the distribution (Salvadori et al. 2007; Kottegoda and Rosso 2008). If $k=0$, GEV reduces to an EV1 distribution (lower and upper unbounded, that is, with a domain of existence ranging from $-\infty$ to $+\infty$ ). If $k<0$, GEV rep-resents an EV2 (upper unbounded but lower bounded, that is, ranging from $\epsilon+\alpha / k$ to $+\infty)$; $k>0$ returns an EV3 (lower unbounded but upper bounded, that is, ranging from $-\infty$ to $\epsilon+\alpha / k)$. We use EV1, EV2, and EV3 to in-dicate extreme value distributions of type I, II, and III, respectively (Kottegoda and Rosso 2008).

For design purposes, extreme precipitations are investigated considering as a random variable of interest the maximum annual precipitation depth $H(D)$ over a fixed duration $D$ and calculating its quantile with a fixed level of probability $F$ or return period $T$. The quantile, indicated as $h(D, F)$, or alternatively $h(D, T)$, is also known as depth-duration-frequency (DDF) curve (Chow et al. 1988). The parameters of DDF curves are estimated at a site from time series of annual maxima of precip-itation at different durations (generally 1, 3, 6, 12, and $24 \mathrm{~h}$ ). The curves include a first set of parameters (namely, $a_{1}$ and $n$, see section $\left.3 a\right)$ relating $h(D, F)$ to $D$ and a second set $(\epsilon, \alpha$ and $k)$ that links $h(D, F)$ to $F$.

The orographic effect on precipitation enhancement, and hence the influence of orography on precipitation climatology, has been widely documented in the past (Doswell et al. 1998; Buzzi et al. 1998; Kieffer Weisse and Bois 2001; Rotunno and Ferretti 2001; Lin et al. 2001; Badas et al. 2006; Ebtehaj and Foufoula-Georgiou 2010). On the contrary, to our knowledge, there are only two works specifically dealing with the effect of relief on the spatial variability of DDF parameters, that is, Allamano et al. (2009) and Blanchet et al. (2009). Allamano et al. (2009) focus their attention on the variability of $a_{1}$ and $n$ with elevation. Blanchet et al. (2009) investigate the spatial variability of $\epsilon, \alpha$, and $k$ over Switzerland. They consider only snow events.

Here, we investigate the orographic signature (i.e., the combined effect of atmospheric circulation and orogra-phy) on extreme precipitation and, in particular, on the spatial variability of DDF curve parameters. We focus on the Italian territory because it presents features (such as a complex orography and a variety of precipitation dy-namics and regimes) that can assist in this evaluation. We estimate the complete set of DDF parameters for 1494 sites. We analyze the spatial variability of DDF parameters. In addition, we investigate possible patterns of these pa-rameters with elevation and an atmospheric index, namely, the vertically integrated atmospheric moisture flux $\mathbf{J}$. This index is able to characterize the synoptic transport of vapor in the atmosphere. In this way, it has been possible to evaluate the link between parameter values, moist air cir-culation, and orography.

In section 2, a mean precipitation climatology for the study area is given, together with information about the data used. In section 3, the DDF is introduced, together with the vector $\mathbf{J}$. In section 4 , results are reported and discussed.

\section{Background and data}

\section{a. Mean annual precipitation over Italy}

Italy covers a latitudinal range between $\sim 47^{\circ}\left(47.098^{\circ}\right.$, South Tyrol $)$ and $\sim 36^{\circ} \mathrm{N}\left(36.638^{\circ}\right.$, Sicily; or up to $\sim 35.3^{\circ}$ considering Lampedusa) and a longitudinal range between $\sim 7^{\circ}\left(6.674^{\circ}\right.$, Piedmont) and $\sim 18^{\circ} \mathrm{E}\left(18.542^{\circ}\right.$, Salento). The main peninsula is surrounded by the Mediterranean Sea on three sides. It is connected to the European continent on the northern side by means of the Alpine chain. This last represents the main orographic barrier to moist air circulation together with the Apennines chain, which crosses the entire peninsula from north to south (Frei and Schär 1998; Costa et al. 2001; Rudari et al. 2005; Brunetti et al. 2009). In Fig. 1a, 
a)
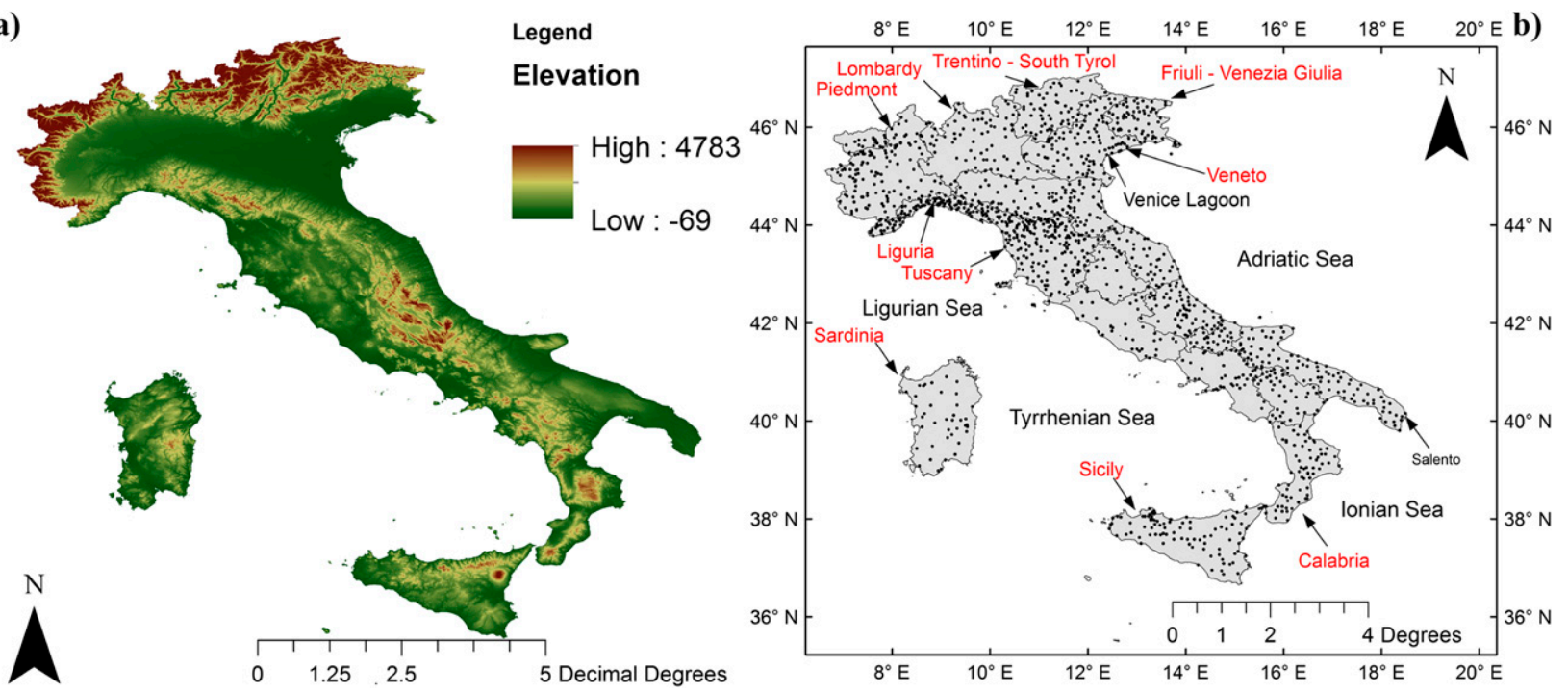

FIG. 1. (a) DTM of the study area (90-m horizontal resolution). The Alps and the Apennines are the west-east and the north-south mountainous chains in the upper central parts, respectively. (b) Position of the 1494 sites, together with the geographical terms mentioned in the text. Administrative regions are marked in red.

a digital terrain model (DTM) of the study area is given (90-m horizontal resolution).

In northern Italy, precipitation events are usually generated by cyclonic areas centered either in the North Atlantic Ocean (Rudari et al. 2005) or near the Iberian Peninsula (Buzzi et al. 1998). Usually, these propagate up to the Gulf of Lion and the Gulf of Genoa, which are particularly prone to the formation of localized cyclones during all seasons (Trigo et al. 1999; Maheras et al. 2001). Wind circulation in the same area is characterized by strong vorticity and high speeds at the sea surface (Zecchetto and De Biasio 2007). These atmospheric patterns, coupled with orographic enhancement, cause relatively high amounts of precipitation over Liguria and northern Tuscany throughout the year (mean annual precipitation of $1500-2200 \mathrm{~mm} \mathrm{yr}^{-1}$ ) and over the first topographic barriers of the northern Piedmont, Lom-bardy, Veneto, and Friuli-Venezia Giulia regions (mean annual precipitation of $1500-2500 \mathrm{~mm} \mathrm{yr}^{-1}$ ). On the contrary, leeward slopes are characterized by less amounts of annual mean precipitation (800-1200 mm $\mathrm{yr}^{-1}$; Frei and Schär 1998). These include the northern versants of Liguria, the Adriatic coast, or the TrentinoSouth Tyrol region. For an exhaustive precipitation climatology over northern Italy, see the maps reported in Brunetti et al.(2009). These show that maxima in mean annual pre-cipitation over northern Italy are located over relevant orographic obstacles to moist air circulation. This attests to the coupling between precipitation climatology and orography.

As for southern Italy, precipitation is dominated by convective systems (Gabriele and Chiaravalloti 2013), by a southward gradient toward concentrated events (Cortesi et al. 2012; Coscarelli and Caloiero 2012), and by cyclones over the Tyrrhenian and Ionian Seas (Trigo et al. 1999; Maheras et al. 2001), especially during winter. These determine amounts of mean annual precipitation on the windward coasts of $1000-1300 \mathrm{~mm} \mathrm{yr}^{-1}$ in northern and eastern Sicily and $1200-1800 \mathrm{~mm} \mathrm{yr}^{-1}$ over the Calabria Apennines (Diodato 2005; Cannarozzo et al. 2006; Coscarelli and Caloiero 2012).

Case studies dealing with the statistical characterization of extreme precipitation over Italy are numerous, but they are usually focused on portions of the entire territory. As examples, refer to Brunetti et al. (2001), (2002); Crisci et al. (2002); Bonaccorso et al. (2005); Boni et al. (2006); Di Baldassarre et al. (2006); Norbiato et al. (2007); or Allamano et al. (2009). To our knowledge, this is the first contribution that systematically investigates the variability of DDF parameters over the whole Italian territory.

\section{b. The data}

Maximum annual precipitation at different durations (namely $1,3,6,12$, and $24 \mathrm{~h}$ ) in Italy has been systematically collected by the former National Hydrographic and Mareographic Service (established in 1917). Since 1998, the same data have been collected by the regional environmental protection agencies. Nowadays, data are available from the 20 regional environmental protection agencies and partly online (www.isprambiente. gov.it/it/progetti/progetto-annali), where it is possible to consult the electronic version of the annual reports. These provide meteorological observations in the 

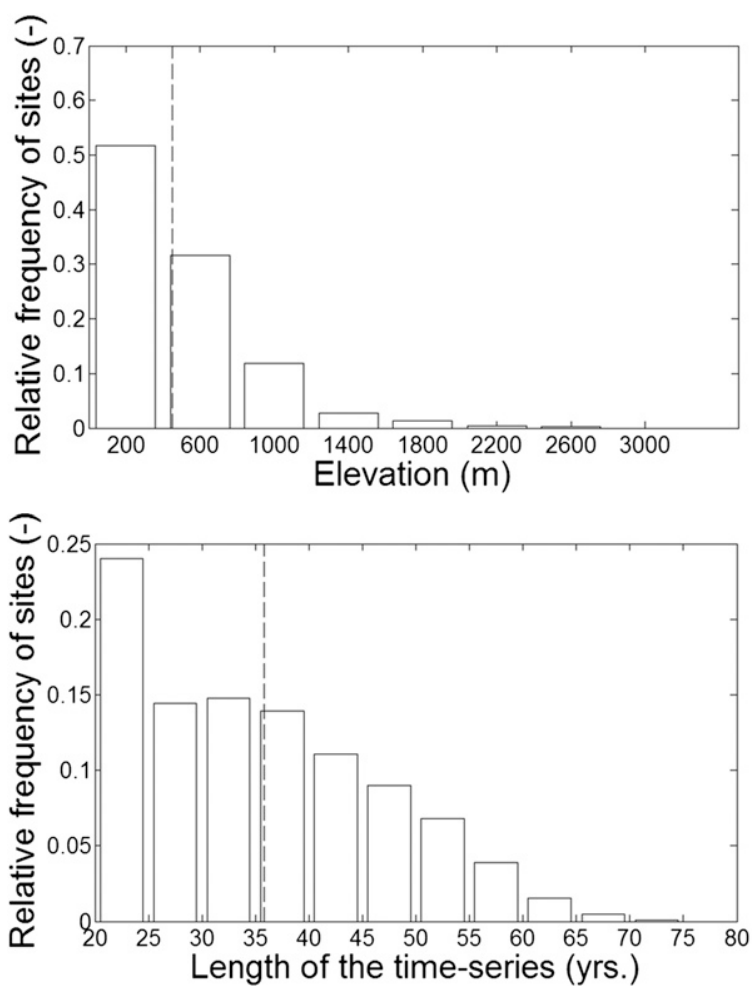

FIG. 2. (a) Elevation and (b) cardinality distribution of the 1494 sites considered. Data are in relative frequency of the sites. The vertical dashed lines represent mean elevation of the sites in (a) and mean length of the available time series in (b).

first part, including annual maxima of precipitation for different durations (usually in Tables 3 and 4 of section $\mathrm{B})$.

Here, we collected 2114 time series, with a sample length $N$ in the interval $1 \leq N \leq 74$ years. We opted for considering only time series with a length $\geq 20$ years. The final dataset includes 1494 stations. Setting a higher threshold (e.g., 40 or 50 years) would improve the estimation of parameters but would cause a strong decrease in the number of stations considered (equal to 952 and 535 , respectively).

In Fig. 1b, time series locations are reported over the Italian territory. In the same figure, geographical places mentioned in the following are given, for sake of clarity. In Fig. 2a, a histogram of the elevation distribution of the sites is reported. The vertical dashed line indicates the average elevation of sites (equal to $449.5 \mathrm{~m}$ MSL). Many of the sites $(\sim 50 \%)$ are placed at an elevation $\leq 400 \mathrm{~m}$ MSL. On the contrary, the percentage of sites at high elevations (e.g., $>2000 \mathrm{~m}$ MSL) is rather low $(\sim 1 \%)$. In Fig. 2 b, a histogram with the sample cardinality of the sites is shown. The vertical dashed line indicates the average length of the 1494 time series (equal to 35.8 years). Its standard deviation is equal to 11.54 years. First, second, and third quartiles are equal to 26 , 34 , and 44 years, respectively.

\section{Methods}

\section{a. Statistical characterization of extreme precipitation: $D D F$}

Here, we assume a stationary probabilistic model describing extreme precipitation of short durations at a given site. Although a number of works are currently available that deal with nonstationarity issues on the assessment of precipitation quantiles (De Michele et al. 1998; Brunetti et al. 2001; Cislaghi et al. 2005; Milly et al. 2008), the average length of available time series of ex-treme precipitation (Fig. 2) is not sufficient to investigate possible long-term variabilities of DDF parameters. In fact, these kinds of analysis usually employ multicentury data series (Cislaghi et al. 2005). Moreover, here we fo-cus on the spatial variability of parameters and quantiles, with respect to moist air circulation and orography, rather than on possible variability in time.

Let $D$ be the size of the temporal window (in the next $1 \leq D \leq 24 \mathrm{~h}$ ) and $H(D)$ be the maximum annual value of the precipitation depth for the duration $D$. According to Salvadori and De Michele (2001) and Salvadori et al. (2007), here we assume $H$ as statistical simple scale invariant with $D$. Therefore, $\forall \lambda \geq 1$, the cumulative distribution function $F$ of the variable $H(\lambda D)$ is equal to the distribution of $H(D)$ multiplied by a power law function of $\lambda$, that is, $\lambda^{n}$ :

$$
F[H(\lambda D)]=F\left[\lambda^{n} H(D)\right] .
$$

Here, $0<n<1$ is a constant scaling exponent. Inverting Eq. (1), it is possible to write a similar equation in terms of quantiles with a level of probability $F$ as $h(\lambda D, F)=\lambda^{n} h(D, F)$. In addition, it is possible to derive from Eq. (1) another equation in terms of statistical moments $E[\cdot]$ of order $r$ with respect to the origin $E\left[H^{r}(\lambda D)\right]=\lambda^{r n} E\left[H^{r}(D)\right]$. In particular, for $r=1$, that is, the mean, $E[H(\lambda D)]=\lambda^{n} E[H(D)]$, or equivalently, $E[H(D)]=D^{n} E[H(1)]$. For details about the scale invariance of annual maxima of precipitation with duration, refer to Kottegoda and Rosso (2008, Eq. 7.3.3).

The ratio between the quantile $h(\lambda D, F)$ and the firstorder statistical moment $E[H(\lambda D)]$, that is, the mean, is denominated normalized quantile $w_{F}$ (or $w_{T}$ in terms of return period $T)$. It is the quantile of the variable $W$. This is invariant with the duration: $w_{F}=h(\lambda D, F) /$ $E[H(\lambda D)]=h(D, F) / E[H(D)]=h(D=1, F) / E[H(1)]$. Consequently, the $F$ th quantile of $H(D)$ can be written as

$$
h(D, F)=E[H(D)] w_{F}=a_{1} D^{n} w_{F},
$$


where $a_{1}=E[H(1)]$. If the GEV distribution is used to describe $H(D)$, then the normalized quantile has the following expression: $w_{F}=\epsilon+\alpha / k\left\{1-[-\ln (F)]^{k}\right\}$. The parameter $\epsilon \in R$ is the position, $\alpha>0$ is the scale, and $k \in R$ is the shape parameter (Kottegoda and Rosso 2008). Since $W$ is not dependent on $D$, the estimation of the parameters $(\epsilon, \alpha$, and $k)$ in $w_{F}$ can be done by making the pooling of the data series for the five durations $(1,3,6$, 12 , and $24 \mathrm{~h}$ ), once normalized respective to the relative mean. Thus, considering a minimum time length of 20 years, the correspondent data sample has a minimum cardinality of 100 data.

Equation (2) represents the DDF curve, with level of probability $F$, under the hypothesis of statistical simple scale invariance (Kottegoda and Rosso 2008, Eq. 7.3.5). It is characterized by five parameters: $a_{1}, n, \epsilon, \alpha$, and $k$. ve Parameter $a_{1}$ is the mean value of annual maximum precipitation depth for unit duration. The greater $a_{1}$ is, the greater the quantile $h(D, F)$ is for a given duration and a given $F$. As for the scaling exponent $n$, the higher the value of this parameter is, the higher $h(\lambda D, F)$ is, at same level of $F$ and for the same duration. Thus, $n$ rules the variability of $h(\lambda D, F)$ with respect to $h(D, F)$. The scale parameter $\alpha>0$, the position parameter $\epsilon$, and the shape parameter $k$ rule the value of $w_{F}$ for a given $F$. In particular, the position parameter determines the location of the center of the distribution, although it is not equal either to the mean or to the median (Blanchet et al. 2009). The scale parameter describes the spread of the distribution (Blanchet et al. 2009). As already mentioned, the value of $k$ has physical implications on the type of random variable (unbounded, upper or lower bounded).

The DDF parameters at a site are estimated from observed time series of maximum annual precipitation at five different durations $(1,3,6,12$, and $24 \mathrm{~h}$ ) by us-ing 1$)$ the least squares method to estimate the mean value of annual maximum precipitation depth for unit duration $a_{1}$ and the scaling exponent from a linear re-

gression of $\ln \{E[H(D)]\}$ against $\ln (D)$ and 2) the method of $\mathrm{L}$ moments to evaluate $\epsilon, \alpha$, and $k$. Refer to Kottegoda and Rosso (2008) for details. A KolmogorovSmirnov goodness-of-fit test has been performed on each data series to verify the hypothesis of GEV distribution for the data. The hypothesis of simple scale invariance has been verified at each site by estimating $n$ for different order moments, that is, $n(r)$ with $r=1,2,3,4$, and by checking that its variability is negligible (Salvadori and De Michele 2001). To this aim, the coefficient

$\Delta n_{1-4}=|[n(1)-n(4)] / n(1)|$ is calculated for each time series. Hereinafter, the variability of $n(r)$ will be considered as negligible if $10 \% \leq \Delta n_{1-4} \leq 20 \%$ (Salvadori and De Michele 2001).

\section{b. Physical characterization of extreme precipitation:}

The vertically integrated atmospheric moisture flux

We consider here the vertically integrated atmospheric moisture flux $\mathbf{J}$. The index describes the synoptic transport of vapor in the atmosphere. This is an important parameter for the feeding of extreme events (Rudari et al. 2005). Here, $\mathbf{J}$ has been calculated using the following definition:

$$
\mathbf{J}=\left(J_{u}, J_{v}\right)=-\frac{1}{g} \int_{p_{s}}^{p_{t}} q \mathbf{V} d p,
$$

where $J_{u}$ and $J_{v}$ are the zonal (i.e., in the west-east direction) and meridional (i.e., in the north-south direction) components of $\mathbf{J}$, respectively; $\mathbf{V}$ is the wind velocities vector; $q$ is the atmospheric specific humidity; $g$ is the gravitational acceleration; and $p_{s}$ and $p_{t}$ are the pressures at the surface and top of the atmosphere $\left(p_{t}=\right.$ $50 \mathrm{hPa}$ ), respectively.

As a first attempt, we used here the modal direction of $\mathbf{J}(\hat{\mathbf{J}})$ evaluated starting from a sample of data of extreme events. Data comes from the 40-yr European Centre for Medium-Range Weather Forecasts (ECMWF) Re-Analysis (ERA-40; Uppala et al. 2004). In particular, ERA-40 contains observations of atmospheric thermo-dynamic fields in the period from September 1957 to August 2002. Even if this period does not cover the last decade, it is coherent with the average period covered by available data series. In addition, it presents a remarkable length. This is useful to individuate the relevant proper-ties of the atmospheric circulation over the study area.

ERA-40 observations were reanalyzed using a 6-hourly three-dimensional variational version (3DVAR) of the ECMWF data assimilation system. ERA-40 is available at the primary hours of $0000,0600,1200$, and 1800 UTC. The assimilating model uses a coarser T159 spectral truncation (horizontal resolution of approximately $125 \mathrm{~km}$ ) with a fully operational 60-level vertical resolution (Uppala et al. 2005). The horizontal resolution of the reanalyzed atmospheric fields, used in this study, is $0.5^{\circ}$ in latitude and longitude. The horizontal resolution should be increased when considering air circulation at the local scale, but this is out of the scope of the use of the $\mathbf{J}$ vector in this contribution. Data are vertically distributed on 23 pres-sure levels from 1000 (surface level) to $1 \mathrm{hPa}$. For each extreme event, the reanalyzed fields of specific humidity and wind from ERA-40 were employed to characterize the meteorological situations over an area extending from $30^{\circ}$ to $66^{\circ} \mathrm{N}$ and from $12^{\circ} \mathrm{W}$ to $43^{\circ} \mathrm{E}$. The four time instances of 0000, 0600, 1200, and 1800 UTC have been considered.

The mode $\hat{\mathbf{J}}$ is defined as the most frequent direction of $\mathbf{J}$ in the meteorological system. It is assumed here as 


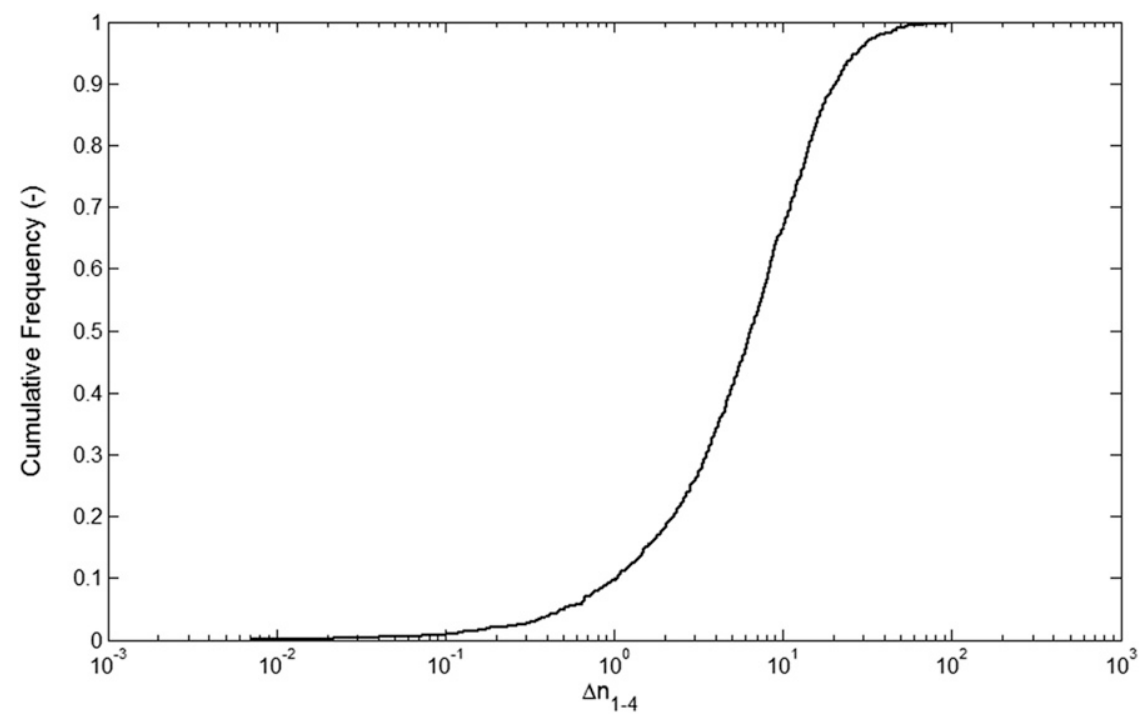

FIG. 3. Cumulative frequency of $\Delta n_{1-4}$.

representative of the directions of the synoptic transport of vapor over the area of study during extreme events.

\section{Results and discussion}

Results are organized in four subsections as follows: in section $4 \mathrm{a}$, the tests of the simple scale invariance of precipitation with the duration and goodness-of-fit tests of GEV distribution are reported. Then, in section $4 \mathrm{~b}$, we comment on the spatial variability of $a_{1}, n, \alpha, \epsilon$, and $k$ and their link with precipitation climatology and relief. In sections $4 \mathrm{c}$ and $4 \mathrm{~d}$, we focus on the spatial variability of quantiles and on the effect of elevation on the variability of the entire set of parameters, respectively.

\section{a. Scale invariance and GEV goodness-of-fit tests}

Figure 3 reports the cumulative frequency of $\Delta n_{1-4}$. This difference is $\leq 10 \%$ at roughly $70 \%$ of the sites and $\leq 20 \%$ at roughly $90 \%$ of the sites. Thus, following Salvadori and De Michele (2001), we can consider the simple scale invariance of $H$ with the duration as verified as a first approximation.

On each data series, we applied the KolmogorovSmirnov test to check the adequacy of the GEV distribution to represent the variability of $W$ (normalized variable). This test did not reject the null hypothesis of GEV distribution for any data series, with a level of significance equal to 0.05 .

\section{b. The orographic signature on extreme precipitation}

\section{1) PARAMETERS $a_{1}$ AND $n$}

Figure 4a gives a spatial interpolation of the estimates of the mean value of annual maximum precipitation depth for unit duration $\left(a_{1}\right)$. It has been obtained with an inverse distance weighted (IDW) algorithm. Similarly, in Fig. 4b, a spatial interpolation of the scaling exponent is reported. In Figs. $4 \mathrm{a}$ and $4 \mathrm{~b}$, the contour line for the elevations $z=100$ and $1000 \mathrm{~m} \mathrm{MSL}$ are given. Point values of $a_{1}$ and $n$ span between 10 and $81.5 \mathrm{~mm}$ $\mathrm{h}^{-1}$ and between 0.04 and 0.62 , respectively. In this work, IDW has been chosen as the interpolation technique mainly because it is simple and straightforward to interpret. In addition, it has been widely applied in the literature ( $\mathrm{Lu}$ and Wong 2008). Recent works, such as Thibaud et al.(2013), show that more complex approaches can im-prove the spatial analysis of extreme precipitations. Nonetheless, the main aim here is to assess the general patterns of spatial variability of parameters and quan-tiles over the study area. To this aim, IDW is considered as a first step (Dirks et al. 1998).

The maxima of $a_{1}$ are located in Liguria, in FriuliVenezia Giulia, and at the southeastern coasts of Sicily and Calabria. Other areas presenting high values of $a_{1}$ are the Tyrrhenian coast, Salento, and the northwestern Alps. On the contrary, minima are located on the inner Alpine chain, in Sardinia, and along the Adriatic coast. These areas of maxima (minima) correspond to areas of maximum (minimum) mean precipitation, as described in section 2a.

The scaling exponent shows spatial patterns that are positively dependent on the orography. This is supported by low values of $n$ within the entire Po valley and at the central and southern Italian coasts and by gradual increasing of $n$ approaching mountains (both in the Alps and Apennines). In general terms, the scaling exponent is high in areas where $z \geq 1000 \mathrm{~m} \mathrm{MSL}$. As already said, $n$ affects the variability of the quantiles of maximum 


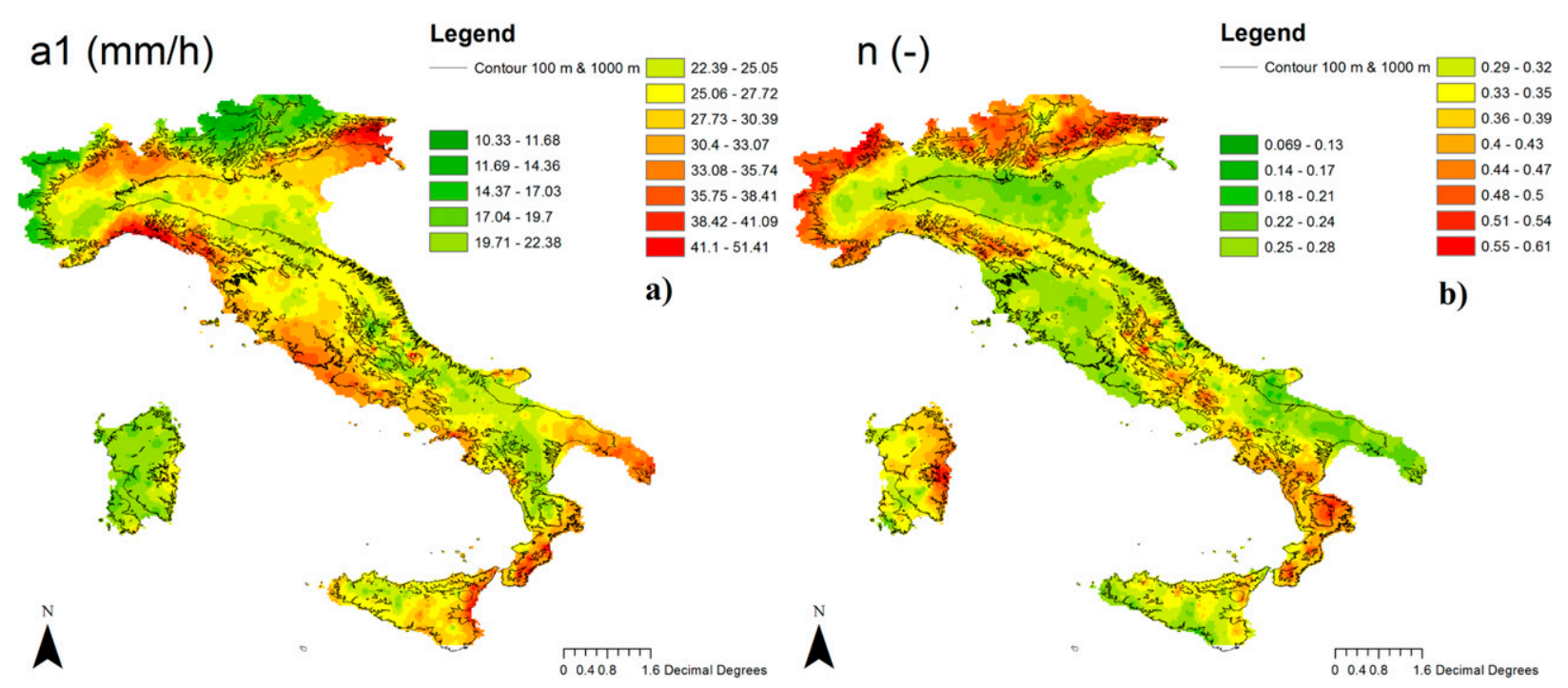

FIG. 4. IDW interpolation of (a) $a_{1}$ and (b) $n$ point estimates over the Italian territory.

precipitation of a given duration $\lambda D$, with respect to those relative to $D$. Therefore, this result suggests that extreme precipitation variability with the duration increases, when increasing the site elevation.

From Fig. 4a, the mean value of annual maximum precipitation depth for unit duration is mainly driven by the coupled effect of precipitation climatology and orography. In fact, maxima of this parameter are located in areas of precipitation enhancement by means of relief. From Fig. 4b, the scaling exponent seems to be driven by orography alone. This conclusion is confirmed by the results in Figs. 5-8, where some topographic sections at constant latitude (longitude) are reported, together with values of $a_{1}$ and $n$ estimated at sites falling within a latitude (longitude) band centered in the section $\pm 0.05^{\circ} \mathrm{N}(\mathrm{E})$.

Figures 5 and 6 show that, generally, the mean value of annual maximum precipitation depth for unit duration is maximal when considering the first windward slope facing the sea. On the contrary, it drops abruptly when crossing it. Also, the parameter increases in proximity of inner windward barriers, but point values are usually lower the farther the barrier is from the moist air source. As a consequence, points at similar elevation, but subjected to different dynamics as for moist air circulation, show very different values of mean annual maximum precipitation depth for unit duration (greater in windward cases than in the leeward ones). Figures 7 and 8 , on the contrary, show that the variability of the scaling ex-ponent reproduces the orographic variability very well.

\section{2) PARAMETERS $\alpha, \epsilon$, AND $K$}

In Figs. 9a-c, IDW interpolations of the local estimations of the scale, position, and shape parameters, respectively, are reported over the whole Italian territory. In the figures, we report also the isolines for $z=100$ and $1000 \mathrm{~m}$ MSL.

Parameters $\alpha$ (i.e., scale) and $\epsilon$ (i.e., position) show a reduced variability over the entire peninsula. In fact, $\sim 70 \%$ of values of $\alpha$ are held between 0.2 and 0.3 over a whole observed range that spans between 0.19 and 0.66 . As for $\epsilon, \sim 95 \%$ of values are held between 0.7 and 0.9 . Interpolations show that $\alpha$ has a slight southward increasing trend, with peaks in Sardinia. Parameter $\epsilon$ presents a slight southward decreasing trend. Therefore, broadly speaking, the position (i.e., the center) and scale (i.e., the spread) of the distribution of extreme precipitation of short durations over the entire study area have a very reduced variability. As for the shape parameter, on the contrary, Fig. 9c shows that it is highly variable over the territory. It presents both positive and negative values $(-0.72 \leq k \leq 0.43$ over the study area).

\section{c. Quantiles distribution}

In Figs. 10a-e, spatial IDW interpolations of quantiles $h(D, F)$ are reported for $1,3,6,12$, and $24 \mathrm{~h}$, respectively, and for $F=0.98$ (i.e., $T=50$ years) over the whole Italian territory. The contour lines for $z=100$ and $1000 \mathrm{~m}$ MSL are also reported.

Extreme events of unit duration (Fig. 10a) are located over most of the Italian coasts and particularly on the southern ones in Friuli-Venezia Giulia; on the western ones in central Italy; and the eastern ones in Sicily, Calabria, and Sardinia (with maximum values greater than $200 \mathrm{~mm}$ ). Nonetheless, additional areas with high values of $h(D, F=0.98)$ are present over most of the Po valley, over the Venice lagoon, and over the internal Apennines, 

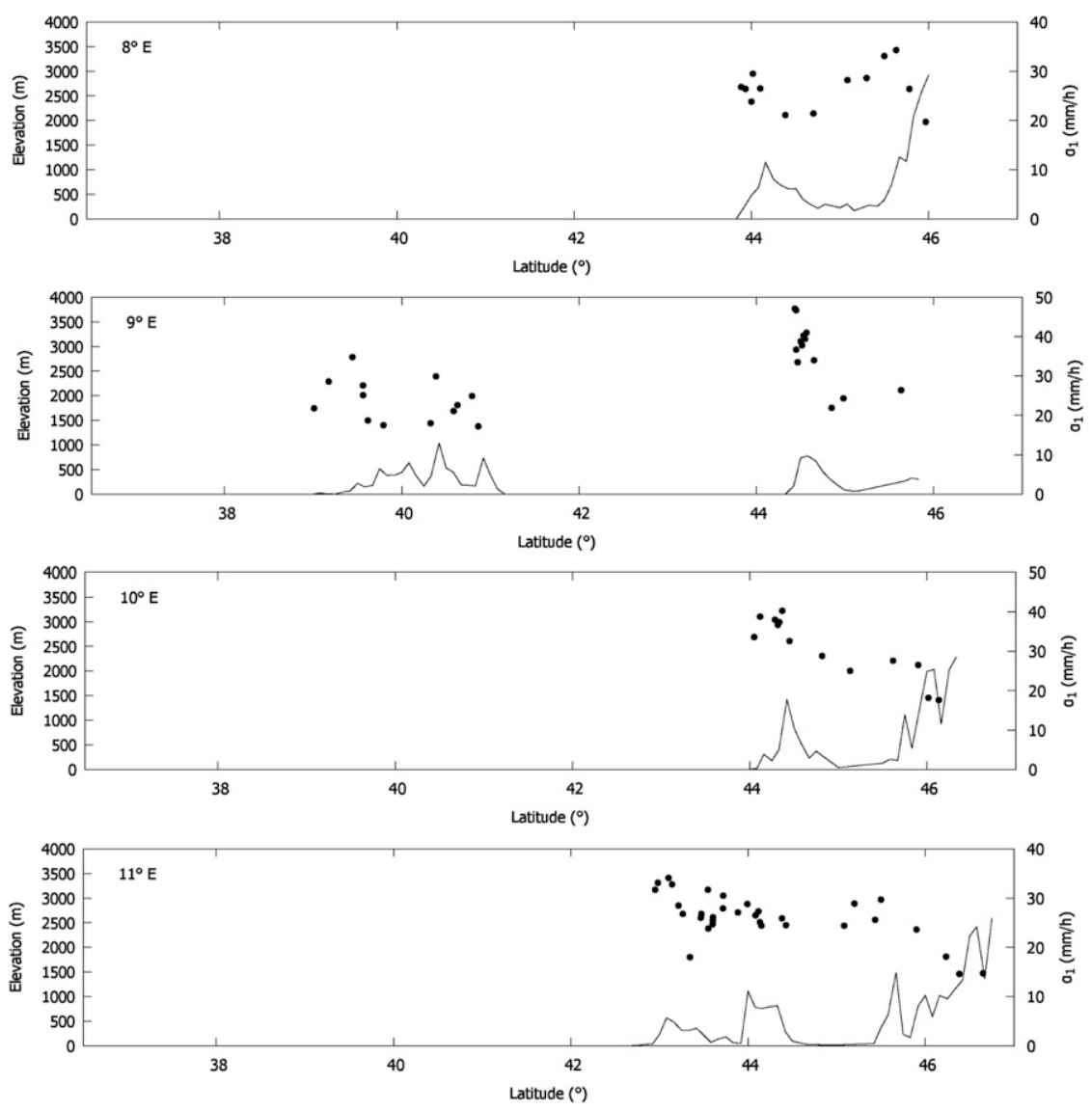

FIG. 5. Altitudinal sections of Italian orography at different longitudes (Fig. 1), together with point values of $a_{1}$ estimated at sites falling in the range $X \pm 0.05^{\circ} \mathrm{E}$, where $X$ is the fixed longitude.

in proximity of high mountains. Figure 10a spatial features recall Fig. 4a.

Passing from $D=1$ to $24 \mathrm{~h}$, the high values of quantiles pertain to more narrow areas. These include the north-western Alps, western Italian coasts, eastern Sardinia, the Friuli-Venezia Giulia region, southern Calabria, and eastern Sicily. The reduction in size and number of areas of high values of quantiles is probably a consequence of the different dynamics of maximum precipitation at 1-h duration (typically convective) and at $24 \mathrm{~h}$ (typically strat-iform). Even if average dimensions of single convective cells are usually much smaller than the usual dimensions of stratiform clouds (Eagleson 2003; Levin and Cotton 2009), this result suggests that areas of local maxima of extreme events of unit duration are more widespread over, for ex-ample, large plains, such as the Po valley. In fact, these areas are extensively prone to the development of con-vection currents because of vertical instability. On the contrary, maxima of extreme events of daily duration are specifically localized in areas where moist air circulation combines with relief. Figures $10 \mathrm{~b}-\mathrm{d}$ show a gradual tran-sition between 1-h and 1-day patterns.
Quantiles of $h(D, F=0.98)$ span between $\sim 17$ and $\sim 220 \mathrm{~mm}$ for $D=1 \mathrm{~h}, \sim 28$ and $\sim 310 \mathrm{~mm}$ for $D=$ $3 \mathrm{~h}, \sim 36$ and $\sim 453 \mathrm{~mm}$ for $D=6 \mathrm{~h}, \sim 38$ and $\sim 678$ $\mathrm{mm}$ for $D=12 \mathrm{~h}$, and $\sim 40$ and $\sim 1010 \mathrm{~mm}$ for $D=24$ $h$. These results show that the occurrence of extreme events of short duration is a very variable process over the entire area.

\section{DDF PARAMETERS AND ATMOSPHERIC CIRCULATION}

In Fig. 11, an IDW interpolation of point values of $\hat{\mathbf{J}}$ is reported. This shows that $\hat{\mathbf{J}}$ is influenced by orographic barriers. In fact, the Apennines cause different directions of flux when considering western and eastern slopes. On the Tyrrhenian side, which is located facing the Atlantic perturbations, the direction of the flux from southwest to northeast is quite homogeneous. On the Adriatic side, the prevalent direction of the flux is from northwest to southeast.

The directions of $\mathbf{J}$,asshowninFig. 11, are compatible with the atmospheric patterns associated with extreme events on the Italian peninsula and in the Mediterranean area (Rudari et al. 2005; Littmann 2000; Aebischer and 

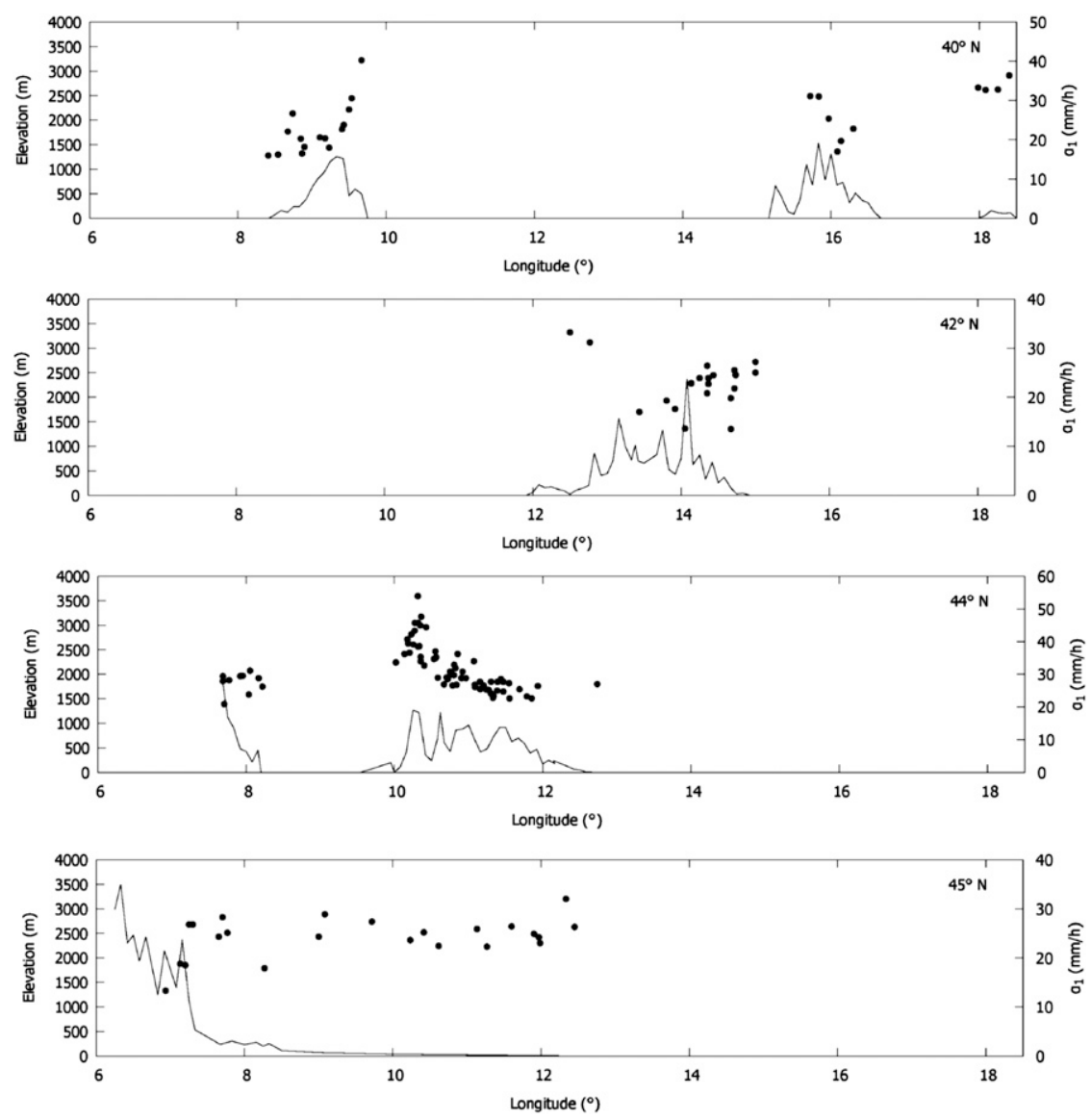

FIG. 6. Altitudinal sections of Italian orography at different latitudes (Fig. 1), together with point values of $a_{1}$ estimated at sites falling in the range $X \pm 0.05^{\circ} \mathrm{N}$, where $X$ is the fixed latitude.

Schär 1998). Moreover, they are related to a well-known source of Mediterranean cyclogenesis (Trigo et al. 1999, 2002; Maheras et al. 2001). Specifically, the $\hat{\mathbf{J}}$ pattern is compatible with cyclogenic activity in the Gulf of Genoa.

The $\hat{\mathbf{J}}$ field shows a good agreement with areas of maxima and minima reported in Fig. 10 and with the variability of $a_{1}$ (mean value of annual maximum precipitation depth for unit duration; Fig. 4). In particular, Fig. 11 points out that the western coasts of the Italian peninsula are mainly windward slopes, while eastern coasts are mainly leeward slopes. Therefore, western coasts present values of $a_{1}$ and of quantiles (at any given duration) that are greater than the ones attributed to eastern coasts. The same can be said when referring to southern and eastern coasts of Calabria and Sicily, respectively, and the southern coasts of Friuli-Venezia Giulia.

\section{$d$. The reverse orographic effect and the upper boundary of extreme precipitation of short durations}

Here, we discuss the variability of DDF parameters with elevation. To this aim, we divided the elevation range in intervals of 50-m width between 0 and $1000 \mathrm{~m}$ MSL and 100-m width between 1000 and 3000 m MSL. We calculated for each elevation range the median value $\tilde{x}$ of $a_{1}, n, \alpha, \epsilon$, and $k$. We then investigated the variability of these with the median elevation of each interval. To this aim, we evaluate regressions between median values of each parameter and elevation. For each parameter, a $95 \%$ confidence interval is provided. If zero is not in-cluded in the confidence interval of the parameter, the contribution of that parameter in the regression will be considered as significant (Kottegoda and Rosso 2008, section 6.2.4.2.). The use of $\tilde{x}$ allowed us to investigate the behavior of the variables, minimizing the effects of noise. Results are reported in Fig. 12.

Median values of $a_{1}$, namely $\widetilde{a_{1}}\left(\mathrm{~mm} \mathrm{~h}^{-1}\right)$, decrease with elevation $z(\mathrm{~m})$. The regression line reads $\widetilde{a_{1}}(z)=$ $-0.0062 z+29.17$, with the coefficient of determination $R^{2}=0.85$. Confidence intervals for the two parameters are $(-0.0071,-0.0053)$ and $(27.94,30.39)$, respectively. Therefore, as median values, the higher the site is, the lower the observed mean of annual maximum precipitation of unit duration is. This result is in contrast 

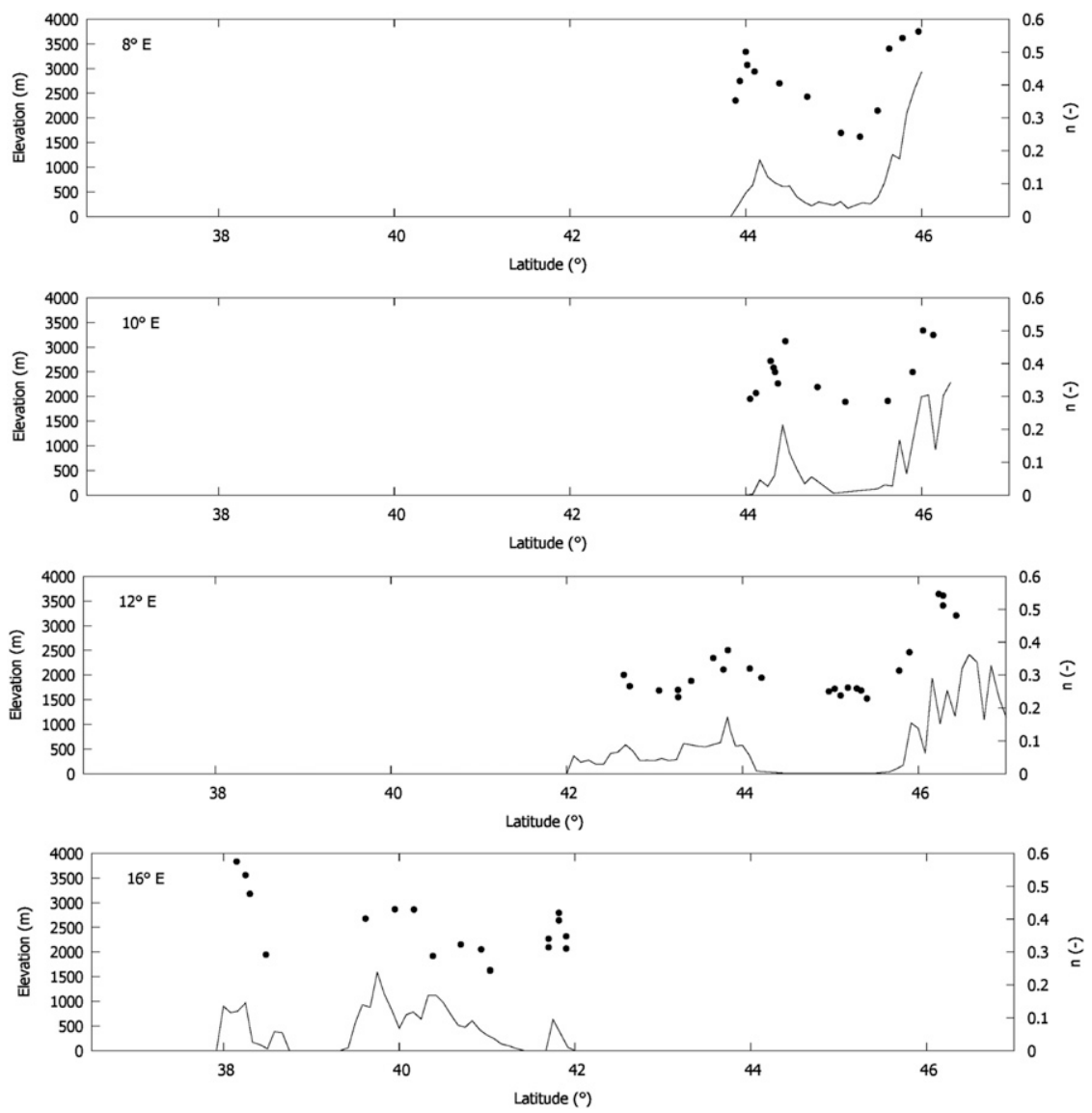

FIG. 7. Altitudinal sections of Italian orography at different longitudes (Fig. 1), together with point values of $n$ estimated at sites falling in the range $X \pm 0.05^{\circ} \mathrm{E}$, where $X$ is the fixed longitude.

with general knowledge about the orographic effect, which broadly states that "precipitation increases with elevation" (Kieffer Weisse and Bois 2001). Nonetheless, the great amount of data used in this analysis supports the evidence that this result should not be site specific. We call this "reverse orographic effect" on extreme precipitation of short durations. This is in agreement with the analysis by Allamano et al. (2009) within the Italian Alpine region.

Parameter $\tilde{n}$ (scaling exponent) is observed to increase with elevation. Moreover, it tends to show a value of $\sim 0.5$ at high elevations, with a regression reading $\tilde{n}(z)=0.54-e^{[-0.00086(z+1452)]}$ and $R^{2}=0.89$. Confidence intervals for the three parameters are (0.4842, 0.6006), (0.000 44, 0.0013), and (864.3, 2039), respectively. This result is in agreement with Figs. 7 and 8 , where we noticed that $n$ reproduces orography. It implies that, again as median values, the higher the site is, the higher $\tilde{n}$ is. It follows that, at higher elevations, extreme events at different durations seem to be more variable, with respect to those at unit duration, than at lower elevations. This result is in agreement with the analysis by Allamano et al. (2009) within the Italian Alpine region.

As for GEV parameters, $\alpha$ and $\epsilon$ (scale and position, respectively) show a slightly decreasing and slightly increasing trend, respectively, with equations $\tilde{\alpha}(z)=$ $-1.29 \times 10^{-5}(z)+0.28$ and $\tilde{\epsilon}(z)=1.98 \times 10^{-5}(z)+$ 0.82 and $R^{2}=0.42$ and 0.49 . Confidence intervals for the two parameters involved in the $\tilde{\alpha}(z)$ regression are $\left(-7.546 \times 10^{-5},-1.843 \times 10^{-5}\right)$ and $(0.2797,0.2939)$, respectively. Confidence intervals for the two parameters involved in the $\tilde{\epsilon}(z)$ regression are $\left(1.267 \times 10^{-5}\right.$, $\left.2.695 \times 10^{-5}\right)$ and $(0.8152,0.8338)$, respectively. Thus, parameter variability is low, as already noted in Fig. 9. The observed decreasing trend of $\alpha$ is in disagreement with the previous analysis by Blanchet et al. (2009). On the contrary, results are in agreement when dealing with the increasing trend of $\epsilon$. Nonetheless, it is worth noting that the analysis by Blanchet et al. (2009) 

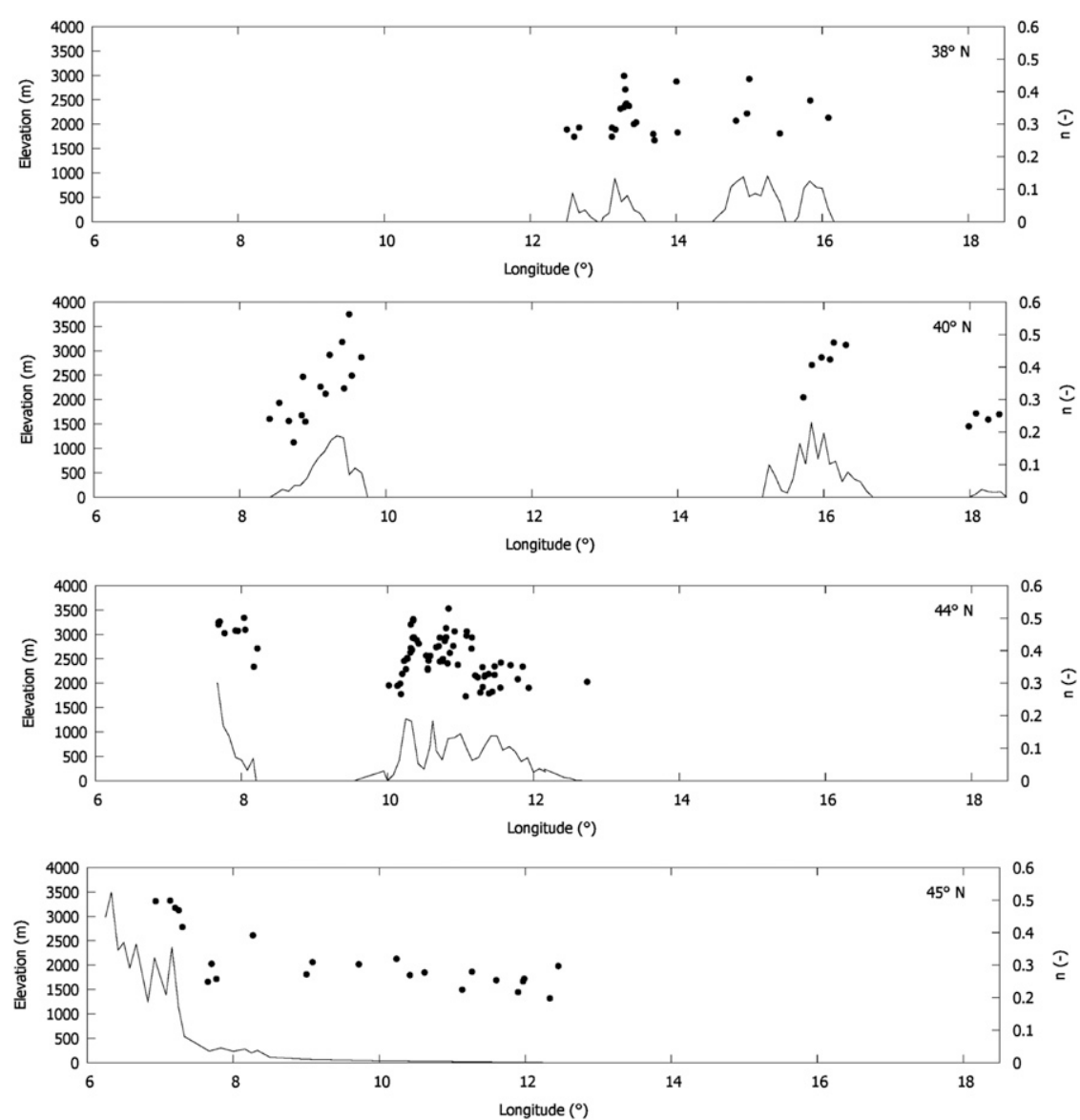

FIG. 8. Altitudinal sections of Italian orography at different latitudes (Fig. 1), together with point values of $n$ estimated at sites falling in the range $X \pm 0.05^{\circ} \mathrm{N}$, where $X$ is the fixed latitude.

is restricted to snow events, and this hampers an exhaustive comparison between the two analyses.

As for $k$, its median value tends to increase with elevation. In this case, the regression line reads $\tilde{k}(z)=$ $4.93 \times 10^{-5}(z)-0.03$ with $R^{2}=0.38$. Confidence intervals for the two parameters are $\left(2.72 \times 10^{-5}, 7.14 \times\right.$ $\left.10^{-5}\right)$ and $(-0.05936,-0.007995)$, respectively. Moreover, median values of $k$ are negative at low elevations but tend to increase and to turn positive at higher elevations. The relation shows that $\tilde{k}$ passes from being negative to positive at $\sim 800 \mathrm{~m} \mathrm{MSL}$. According to Jenkinson $(1955,1969)$, negative values of $k$ denote an upper unbounded and lower bounded probability distribution, while positive $k$, on the contrary, characterizes a distribution lower unbounded, but upper bounded. It follows that, at higher elevations, the extreme precipitation seems to be upper limited. This result is in agreement with the analysis by Blanchet et al. (2009) within the Swiss Alps for snow events.
This analysis outlines the main features of extreme events of short durations at high elevations:

- the mean maximum annual precipitation of unit duration decreases with elevation (reverse orographic effect);

- the quantiles of maximum annual precipitation at durations greater than $1 \mathrm{~h}$ are more variable, with respect to the ones at unit duration, at higher elevations than at the lower ones; and

- extreme events at high elevations are distributed according to an upper bounded probability distribution.

Figure 12 shows that the proposed regressions are good predictors of data at lower elevations and poor predictors at high elevations. This is probably because of the reduced amount of stations at high elevations. Nonetheless, all regressions are significant. We have tested the results shown in Fig. 12, changing (increasing) the threshold on 

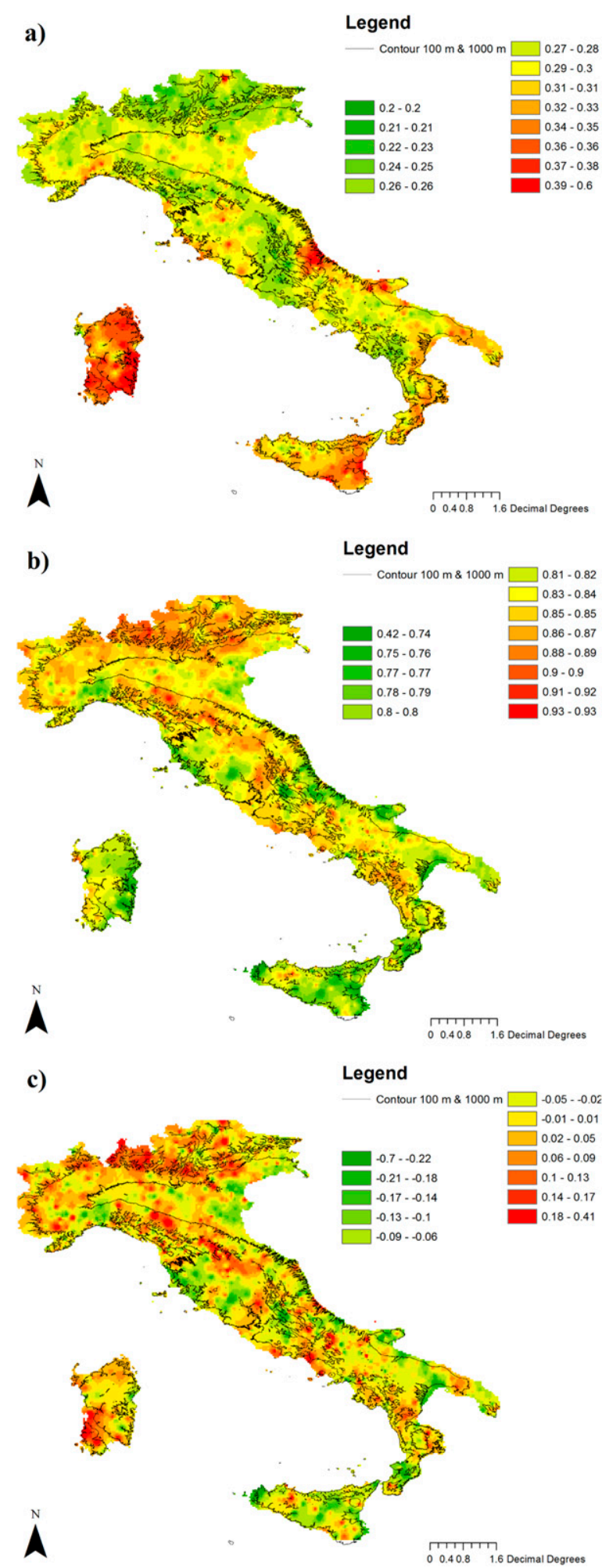

FIG. 9. IDW interpolation of (a) $\alpha$, (b) $\epsilon$, and (c) $k$ point estimates over the Italian territory. sample length ( $\geq 40$ years). This analysis (not showed for brevity) confirmed the results.

Further investigations should address possible effects of rain gauge deficiencies on these estimations. In fact, some features of precipitation events (especially strong winds and snow events) can hamper the correct evaluation of the total amount of precipitation depth (Larson and Peck 1974; Stisen et al. 2012; Avanzi et al. 2014b). Nonetheless, snow events usually have longer durations than rain events (Avanzi et al. 2014a). In addition, catch deficiency lowers when considering rain events instead of snow events (Mizukami and Smith 2012). Conse-quently, extreme precipitation of short durations should be marginally affected by this effect. This holds, for example, when considering the mean value of annual maximum precipitation depth for unit duration $a_{1}$, or the evaluation of the elevation of transition between negative and positive $\tilde{k}$. In addition, catch deficiency decreases with decreasing wind velocities. To our knowledge, no evidence of trends of catch deficiency with mere elevation is available. As a consequence, reverse orographic effect on extreme precipitation should be a characteristic sign of the formation of precipitation events at high elevations.

At this stage, extreme precipitation features at high elevations have been investigated without differentiating among the various meteorological and/or climatological regimes. In this framework, we find a relevant and general feature of extreme precipitation, without making any assumption about the type of event (e.g., stratiform or convective). Nonetheless, separated anal-yses could help, for example, to investigate whether the reverse orographic effect is more typical of a specific regime than others or not. As an example, Zhang et al.(2014) also report decreasing trends of many pre-cipitation indices (e.g., consecutive dry days or annual count of days when daily precipitation $\geq 20$ or $25 \mathrm{~mm}$ ) with elevation in a monsoon area in China.

\section{Conclusions}

Here, we dealt with the effects of atmospheric circulation and orography on extreme precipitation of short durations. We considered 1494 data series of maximum annual precipitation at different durations $(1,3,6,12$, and $24 \mathrm{~h}$ ). We estimated the complete set of parameters of DDF curves at each location with the hypothesis of simple scale invariance. We verified both the scale invariance and the goodness of fit of GEV distribution against data. As a result, DDF parameter variability shows either a coupled climatological-orographic base $\left(a_{1}\right)$ or a pure orographic one $(n)$. On the contrary, $\alpha$ and $\epsilon$ returned a scarce variability over the Italian territory, 


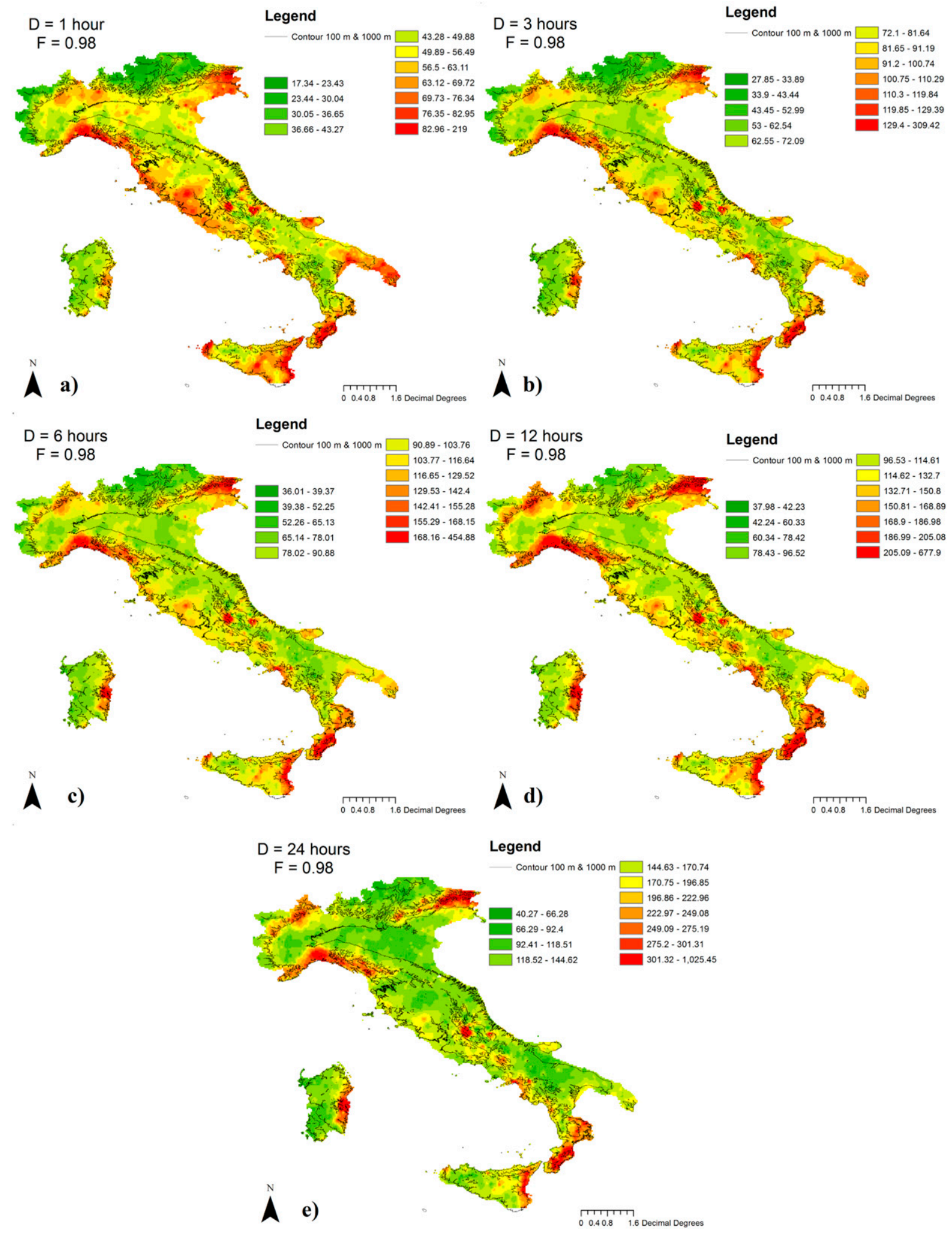

FIG. 10. IDW interpolation of $h(D, F)$ point estimates $(\mathrm{mm})$ for $F=0.98$ and different durations over the Italian territory. 


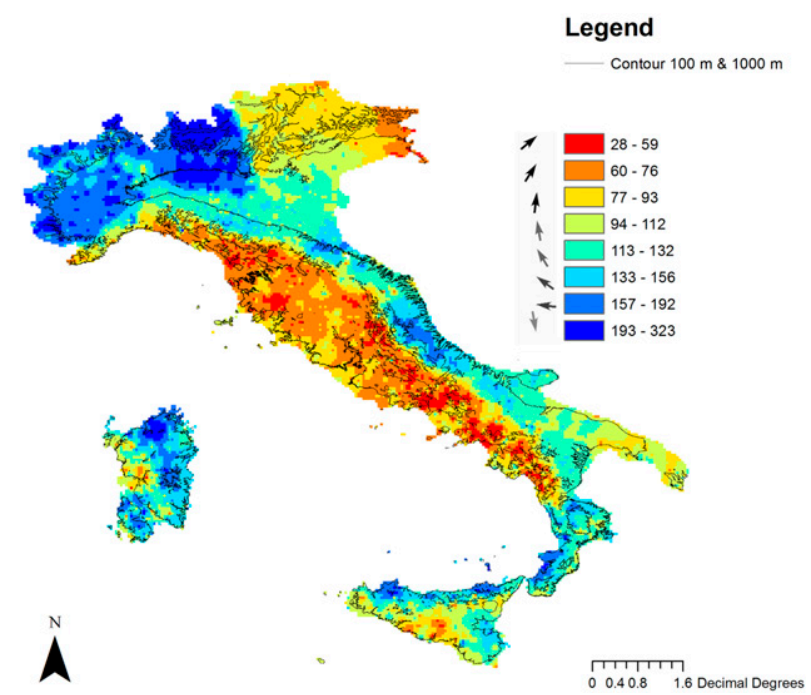

FIG. 11. Modal values of the direction of $\mathbf{J}$ vector over the Italian territory.

while $k$ is shown to be highly variable. When considering quantiles for different $D$ and $T$, some areas of maximum (minimum) concentration are evident. These are strongly correlated to areas of maximum (minimum) mean annual precipitation and with windward (leeward) areas. The impact of atmospheric humidity has been measured through the vertically integrated atmospheric moisture flux. In addition, by analyzing the variability of DDF parameters with elevation, it has been found that median values of $a_{1}$ decrease with elevation (reverse orographic effect). Median values of the scaling exponent increase with elevation and tend to show a value of 0.5 at high elevations. Moreover, median values of the shape parameter $k$ increase with elevation, passing from negative to positive at $\sim 800 \mathrm{~m}$ MSL. As a consequence, extreme events at high elevations over the study area turn out to be upper bounded and more variable at high elevations than at the low ones. They present means of maximum annual precipitation of unit duration that are decreasing with elevation (reverse orographic effect).

Acknowledgments. Meteorological data are extracts from the ERA-40 archive of the European Centre for Medium-Range Weather Forecasts. We thank the Italian Regional Environmental Protection Agencies for having provided the time series of maximum annual precipitation at different durations. We also thank Dr. Joe Turk, Editor, and three anonymous reviewers for having provided useful suggestions to this paper.
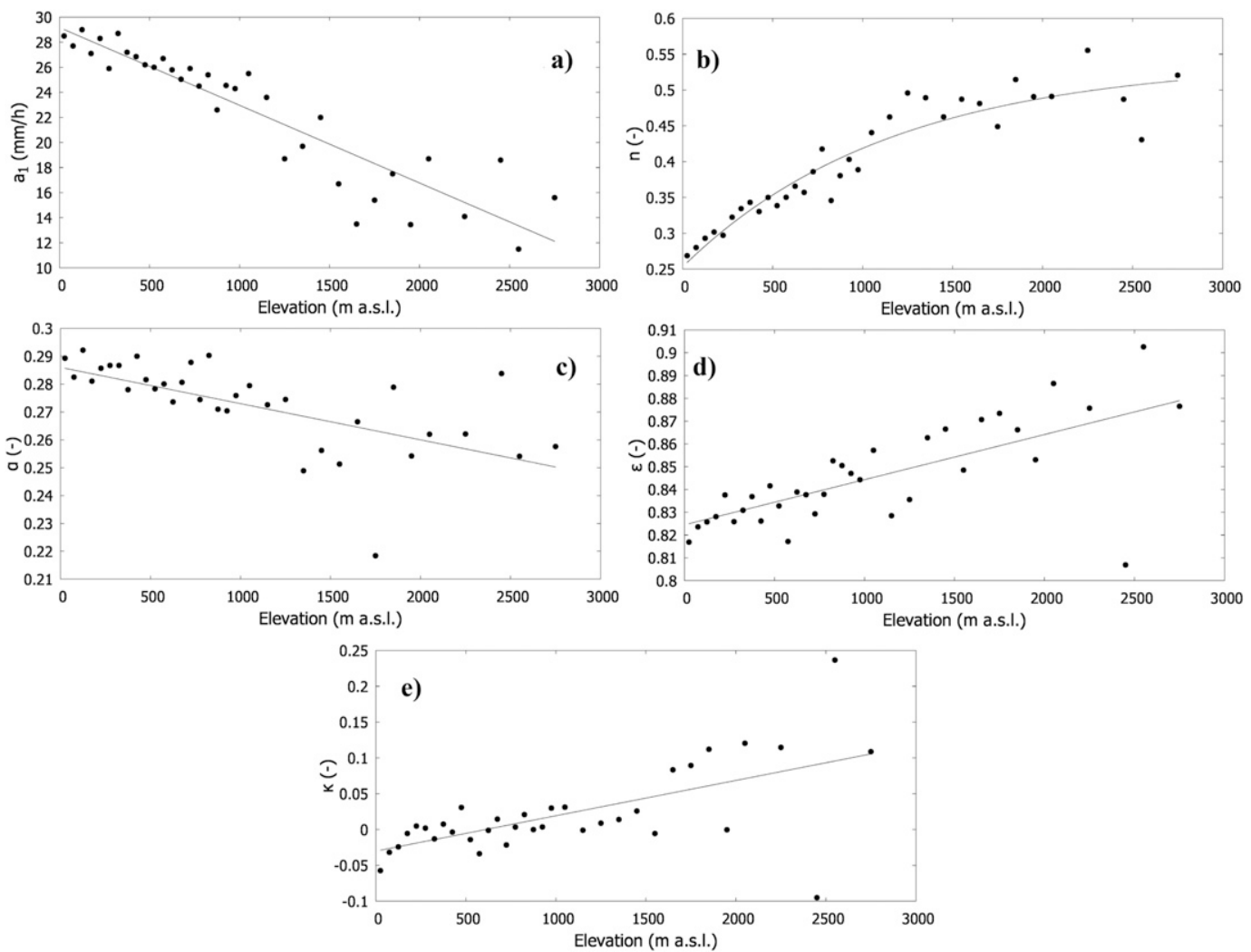

FIG. 12. Median values of the parameters $a_{1}, n, \alpha, \epsilon$, and $k$ as a function of elevation. Dots indicate the estimates for different elevation intervals, while lines the proposed regressions. 


\section{REFERENCES}

Aebischer, U., and C. Schär, 1998: Low-level potential vorticity and cyclogenesis to the lee of the Alps. J. Atmos. Sci., 55, 186-207, doi:10.1175/1520-0469(1998)055<0186:LLPVAC >2.0.CO;2.

Allamano, P., P. Claps, F. Laio, and C. Thea, 2009: A data-based assessment of the dependence of short-duration precipitation on elevation. Phys. Chem. Earth, 34, 635-641, doi:10.1016/ j.pce.2009.01.001.

Alpert, P., 1986: Mesoscale indexing of the distribution of orographic precipitation over high mountains. J. Climate Appl. Meteor., 25, 532-545, doi:10.1175/1520-0450(1986)025<0532: MIOTDO $>2.0 . \mathrm{CO} ; 2$.

— , and Coauthors, 2002: The paradoxical increase of Mediterranean extreme daily rainfall in spite of decrease in total values. Geophys. Res. Lett., 29, 1536, doi:10.1029/ 2001GL013554.

Anders, A. M., G. H. Roe, B. Hallet, D. R. Montgomery, N. J. Finnegan, and J. Putkonen, 2006: Spatial patterns of precipitation and topography in the Himalaya. Spec. Pap. Geol. Soc. Amer., 398, 39-53, doi:10.1130/2006.2398(03).

Avanzi, F., C. De Michele, and A. Ghezzi, 2014a: Liquid-solid partitioning of precipitation along an altitude gradient and its statistical properties: An Italian case study. Amer. J. Climate Change, 3, 71-82, doi:10.4236/ajcc.2014.31007.

,,--- C. Jommi, and M. Pepe, 2014b: A processingmodeling routine to use SNOTEL hourly data in snowpack dynamic models. Adv. Water Resour., 73, 16-29, doi:10.1016/ j.advwatres.2014.06.011.

Badas, M. G., R. Deidda, and E. Piga, 2006: Modulation of homogeneous space-time rainfall cascades to account for orographic influences. Nat. Hazards Earth Syst. Sci., 6, 427-437, doi:10.5194/nhess-6-427-2006.

Barros, A. P., and R. J. Kuligowski, 1998: Orographic effects during a severe wintertime rainstorm in the Appalachian Mountains. Mon. Wea. Rev., 126, 2648-2672, doi:10.1175/ 1520-0493(1998)126<2648:OEDASW > 2.0.CO;2.

Blanchet, J., C. Marty, and M. Lehning, 2009: Extreme value statistics of snowfall in the Swiss Alpine region. Water Resour.

Res., 45, W05424, doi:10.1029/2009WR007916.

Blöschl, G., T. Nester, J. Komma, J. Parajka, and R. A. Perdigão, 2013: The June 2013 flood in the Upper Danube Basin, and comparisons with the 2002, 1954 and 1899 floods. Hydrol. Earth Syst. Sci., 17, 5197-5212, doi:10.5194/hess-17-5197-2013.

Bonaccorso, B., A. Cancelliere, and G. Rossi, 2005: Detecting trends of extreme rainfall series in Sicily. Adv. Geosci., 2, 7-11, doi:10.5194/adgeo-2-7-2005.

Bonacina, L. C. W., 1945: Orographic rainfall and its place in the hydrology of the globe. Quart. J. Roy. Meteor. Soc., 71, 41-55, doi:10.1002/qj.49707130705.

Boni, G., A. Parodi, and R. Rudari, 2006: Extreme rainfall events: Learning from raingauge time series. J. Hydrol., 327, 304-314, doi:10.1016/j.jhydrol.2005.11.050.

Brunetti, M., M. Maugeri, and T. Nanni, 2001: Changes in total precipitation, rainy days and extreme events in northeastern Italy. Int. J. Climatol., 21, 861-871, doi:10.1002/joc.660.

,,--- , and A. Navarra, 2002: Droughts and extreme events in regional daily Italian precipitation series. Int. J. Climatol., 22, 543-558, doi:10.1002/joc.751.

-, G. Lentini, M. Maugeri, T. Nanni, C. Simolo, and J. Spinoni, 2009: 1961-1990 high-resolution northern and central Italy monthly precipitation climatologies. Adv. Sci. Res., 3, 73-78, doi:10.5194/asr-3-73-2009.
Buzzi, A., N. Tartaglione, and P. Malguzzi, 1998: Numerical simulations of the 1994 Piedmont flood: Role of orography and moist processes. Mon. Wea. Rev., 126, 2369-2383, doi:10.1175/ 1520-0493(1998)126<2369:NSOTPF $>2.0 . \mathrm{CO} ; 2$.

Cannarozzo, M., L. Noto, and F. Viola, 2006: Spatial distribution of rainfall trends in Sicily (1921-2000). Phys. Chem. Earth, 31, 1201-1211, doi:10.1016/j.pce.2006.03.022.

Chow, V. T., D. R. Maidment, and L. W. Mays, 1988: Applied Hydrology. McGraw-Hill, $572 \mathrm{pp}$.

Cislaghi, M., C. De Michele, A. Ghezzi, and R. Rosso, 2005: Statistical assessment of trends and oscillations in rainfall dynamics: Analysis of long daily Italian series. Atmos. Res., 77, 188-202, doi:10.1016/j.atmosres.2004.12.014.

Cortesi, N., J. C. Gonzalez-Hidalgo, M. Brunetti, and J. MartinVide, 2012: Daily precipitation concentration across Europe 1971-2010. Nat. Hazards Earth Syst. Sci., 12, 2799-2810, doi:10.5194/nhess-12-2799-2012.

Coscarelli, R., and T. Caloiero, 2012: Analysis of daily and monthly rainfall concentration in Southern Italy (Calabria region). J. Hydrol., 416-417, 145-156, doi:10.1016/j.jhydrol.2011.11.047.

Costa, S., P. Mezzasalma, V. Levizzani, P. P. Alberoni, and S. Nanni, 2001: Deep convection over northern Italy: Synoptic and thermodynamic analysis. Atmos. Res., 56, 73-88, doi:10.1016/S0169-8095(00)00091-0.

Coumou, D., and S. Rahmstorf, 2012: A decade of weather extremes. Nat. Climate Change, 2, 491-496,

doi:10.1038/nclimate1452.

Crisci, A., B. Gozzini, F. Meneguzzo, S. Pagliara, and G. Maracchi, 2002: Extreme rainfall in a changing climate: Regional analysis and hydrological implications in Tuscany. Hydrol. Processes, 16, 1261-1274, doi:10.1002/hyp.1061.

De Michele, C., A. Montanari, and R. Rosso, 1998: The effects of non-stationarity on the evaluation of critical design storm. Water Sci. Technol., 37, 187-193, doi:10.1016/ S0273-1223(98)00332-1.

Di Baldassarre, G., A. Castellarin, and A. Brath, 2006: Relationships between statistics of rainfall extremes and mean annual precipitation: An application for design-storm estimation in northern central Italy. Hydrol. Earth Syst. Sci., 10, 589-601, doi:10.5194/hess-10-589-2006.

Diodato, N., 2005: The influence of topographic co-variables on the spatial variability of precipitation over small regions of complex terrain. Int. J. Climatol., 25, 351-363, doi:10.1002/joc.1131

Dirks, K. N., J. E. Hay, C. D. Stow, and D. Harris, 1998: Highresolution studies of rainfall on Norfolk Island part II: Interpolation of rainfall data. J. Hydrol., 208, 187-193, doi:10.1016/S0022-1694(98)00155-3.

Doswell, C. A., III, C. Ramis, R. Romero, and S. Alonso, 1998: A diagnostic study of three heavy precipitation episodes in the western Mediterranean region. Wea. Forecasting, 13, 102-124, doi:10.1175/1520-0434(1998)013<0102: ADSOTH $>2.0 . \mathrm{CO} ; 2$

Eagleson, P. S., 2003: Dynamic Hydrology. EGU Reprint Series, Vol. 2, Copernicus, $462 \mathrm{pp}$.

Ebtehaj, M., and E. Foufoula-Georgiou, 2010: Orographic signature on multiscale statistics of extreme rainfall: A stormscale study. J. Geophys. Res., 115, D23112, doi:10.1029/ 2010JD014093.

Frei, C., and C. Schär, 1998: A precipitation climatology of the Alps from high-resolution rain-gauge observations. Int. J. Climatol., $\quad \mathbf{1 8}, \quad 873-900$, doi:10.1002/ (SICI)1097-0088(19980630)18:8<873:: $\quad$ AIDJOC255>3.0.CO;2-9. 
Gabriele, S., and F. Chiaravalloti, 2013: Using the meteorological information for the regional rainfall frequency analysis: An application to Sicily. Water Resour. Manage., 27, 1721-1735, doi:10.1007/s11269-012-0235-6.

Gheusi, F., and J. Stein, 2003: Small-scale rainfall mechanisms for an idealized convective southerly flow over the Alps. Quart. J. Roy. Meteor. Soc., 129, 1819-1840, doi:10.1256/qj.02.85.

- H. C. Davies, and J. Stein, 2002: How the Alpine topography induces a climatological precipitation maximum of in autumn over the Lago Maggiore area. 10th Conf. on Mountain Meteorology and MAP Meeting, Breckenridge, $\mathrm{CO}$, Amer. Meteor. Soc., 7.3. [Available online at https://ams.confex.com/ams/ 10Mountain/webprogram/Paper40459.html.]

Gumbel, E. J., 1958: Statistics of Extremes. Columbia University Press, 375 pp.

Houze, R. R., Jr., 1997: Stratiform precipitation in regions of convection: A meteorological paradox? Bull. Amer. Meteor. Soc., 78, 2179-2196, doi:10.1175/1520-0477(1997)078<2179: SPIROC $>2.0 . \mathrm{CO} ; 2$.

Jenkinson, A. F., 1955: The frequency distribution of the annual maximum (or minimum) values of meteorological elements. Quart. J. Roy. Meteor. Soc., 81, 158-171, doi:10.1002/ qj. 49708134804.

_ 1969: Estimation of maximum floods. WMO Tech. Note 98/ WMO 233, $208 \mathrm{pp}$.

Kieffer Weisse, A., and Ph. Bois, 2001: Topographic effects on statistical characteristics of heavy rainfall and mapping in the French Alps. J. Appl. Meteor., 40, 720-740, doi:10.1175/ 1520-0450(2001)040<0720:TEOSCO > 2.0.CO;2.

Kottegoda, N. T., and R. Rosso, 2008: Applied Statistics for Civil and Environmental Engineers. McGraw-Hill, 718 pp.

Koutsoyiannis, D., 2004a: Statistics of extremes and estimation of extreme rainfall: I. Theoretical investigation. Hydrol. Sci. J.,

49, 576-590, doi:10.1623/hysj.49.4.575.54430.

- , 2004b: Statistics of extremes and estimation of extreme rainfall: II. Empirical investigation of long rainfall records. Hydrol. Sci. J., 49, 591-610, doi:10.1623/hysj.49.4.591.54424.

Kunkel, K. E., K. Andsager, and D. R. Easterling, 1999: Long-term trends in extreme precipitation events over the conterminous United States and Canada. J. Climate, 12, 2515-2527, doi:10.1175/1520-0442(1999)012<2515:LTTIEP>2.0.CO;2.

Larson, L. W., and E. L. Peck, 1974: Accuracy of precipitation measurements for hydrologic modeling. Water Resour. Res.,

10, 857-863, doi:10.1029/WR010i004p00857.

Levin, Z., and W. R. Cotton, 2009: Aerosol Pollution Impact on Precipitation: A Scientific Review. Springer, 386 pp.

Lin, Y.-L., S. Chiao, T.-A. Wang, M. L. Kaplan, and R. P. Wenglarz, 2001: Some common ingredients for heavy orographic rainfall. Wea. Forecasting, 16, 633-660, doi:10.1175/ 1520-0434(2001)016<0633:SCIFHO >2.0.CO;2.

Littmann, T., 2000: An empirical classification of weather types in the Mediterranean Basin and their interrelation with rainfall. Theor. Appl. Climatol., 66, 161-171, doi:10.1007/ s007040070022.

Lu, G. Y., and D. W. Wong, 2008: An adaptive inverse-distance weighting spatial interpolation technique. Comput. Geosci.,

34, 1044-1055, doi:10.1016/j.cageo.2007.07.010.

Maheras, P., H. Flocas, I. Partikas, and C. Anagnostopoulos, 2001: A 40 year objective climatology of surface cyclones in the Mediterranean region: Spatial and temporal distribution. Int. J. Climatol., 21, 109-130, doi:10.1002/joc.599.

Milly, P., J. Betancourt, M. Falkenmark, R. M. Hirsch, Z. W. Kundewicz, D. P. Lettenmaier, and R. J. Stouffer, 2008:
Stationarity is dead: Whither water management. Science, $\mathbf{3 1 9}$, 573-574, doi:10.1126/science.1151915.

Minder, J. R., D. R. Durran, G. H. Roe, and A. M. Anders, 2008: The climatology of small-scale orographic precipitation over the Olympic Mountains: Patterns and processes. Quart. J. Roy. Meteor. Soc., 134, 817-839, doi:10.1002/qj.258.

Mizukami, N., and M. B. Smith, 2012: Analysis of inconsistencies in multi-year gridded quantitative precipitation estimate over com-plex terrain and its impact on hydrologic modeling. $J$. Hydrol., 428-429, 129-141, doi:10.1016/j.jhydrol.2012.01.030.

Mott, R., D. Scipión, M. Schneebeli, N. Dawes, A. Berne, and M. Lehning, 2014: Orographic effects on snow deposition patterns in mountainous terrain. J. Geophys. Res. Atmos., 119, 1419-1439, doi:10.1002/2013JD019880.

Mueller, M., 2003: Damages of the Elbe flood 2002 in Germany: A review. Geophysical Research Abstracts, Vol. 5, Abstract 12992.

Norbiato, D., M. Borga, M. Sangati, and F. Zanon, 2007: Regional frequency analysis of extreme precipitation in the eastern Italian Alps and the August 29, 2003 flash flood. J. Hydrol., 345, 149-166, doi:10.1016/j.jhydrol.2007.07.009.

Roe, G. H., 2005: Orographic precipitation. Annu. Rev. Earth Planet.

Sci., 33, 645-671, doi:10.1146/annurev.earth.33.092203.122541.

Rotunno, R., and R. Ferretti, 2001: Mechanisms of intense alpine rainfall. J. Atmos. Sci., 58, 1732-1749, doi:10.1175/

1520-0469(2001)058<1732:MOIAR > 2.0.CO;2.

, and R. A. Houze, 2007: Lessons on orographic precipitation

from the mesoscale alpine programme. Quart. J. Roy. Meteor. Soc., 133, 811-830, doi:10.1002/qj.67.

Rudari, R., D. Entekhabi, and G. Roth, 2005: Large-scale atmospheric patterns associated with mesoscale features leading to extreme precipitation events in northwestern Italy. $A d v . W a-$ ter Resour., 28, 601-614, doi:10.1016/j.advwatres.2004.10.017.

Salvadori, G., and C. De Michele, 2001: From generalized Pareto to extreme values law: Scaling properties and derived features.

J. Geophys. Res., 106, 24063-24070, doi:10.1029/2001JD900091.—_, - N. T. Kottegoda, and R. Rosso, 2007: Extremes in

Nature: An Approach Using Copulas. Springer, 292 pp.—, and F. Durante, 2011: On the return period and design in a multivariate framework. Hydrol. Earth Syst. Sci., 15, 32933305, doi:10.5194/hess-15-3293-2011.

Sarker, R. P., 1966: A dynamical model of orographic rainfall.

MonWea. Rev., 94, 555-572, doi:10.1175/1520-0493(1966)094<0555: ADMOOR $>2.3 . \mathrm{CO} ; 2$.

Silvestro, F., S. Gabellani, F. Giannoni, A. Parodi, N. Rebora, R. Rudari, and F. Siccardi, 2012: A hydrological analysis of the 4 November 2011 event in Genoa. Nat. Hazards Earth Syst. Sci., 12, 2743-2752, doi:10.5194/nhess-12-2743-2012.

Smith, R. B., 2006: Progress on the theory of orographic precipitation. Spec. Pap. Geol. Soc. Amer., 398,1-16, doi:10.1130/ 2006.2398(01).

—, and I. Barstad, 2004: A linear theory of orographic precipitation. J. Atmos. Sci., 61, 1377-1391, doi:10.1175/ 1520-0469(2004)061<1377:ALTOOP>2.0.CO;2.

, Q. Jiang, M. G. Fearon, P. Tabary, M. Dorninger, J. D. Doyle, and R. Benoit, 2003: Orographic precipitation and air mass transformation: An Alpine example. Quart. J. Roy. Meteor. Soc., 129, 433-454, doi:10.1256/qj.01.212.

Stisen, S., A. L. Højberg, L. Troldborg, J. C. Refsgaard, B. S. B. Christensen, M. Olsen, and H. J. Henriksen, 2012: On the importance of appropriate precipitation gauge catch correction for hydrological modelling at mid to high latitudes. Hydrol. Earth Syst. Sci., 16, 4157-4176, doi:10.5194/hess-16-4157-2012. 
Thibaud, E., R. Mutzner, and A. C. Davison, 2013: Threshold modeling of extreme spatial rainfall. Water Resour. Res., 49, 4633-4644, doi:10.1002/wrcr.20329.

Trigo, I. F., T. D. Davies, and G. R. Bigg, 1999: Objective climatology of cyclones in the Mediterranean region.J. Climate, 12,1685-1696, doi:10.1175/1520-0442(1999)012<1685:OCOCIT >2.0.CO;2.

, R. Bigg, and T. Davies, 2002: Climatology of cyclogenesis mechanisms in the Mediterranean. Mon. Wea. Rev., 130, 549-569,

doi:10.1175/1520-0493(2002)130<0549:COCMIT>2.0.CO;2. Uppala, S. M., and Coauthors, 2004: ERA-40: ECMWF 45-year reanalysis of the global atmosphere and surface conditions 1957-2002. ECMWF Newsletter, No. 101, ECMWF, Reading, United Kingdom, 2-21. [Available online at http://old.ecmwf. int/publications/newsletters/pdf/101.pdf.]

, and Coauthors, 2005: The ERA-40 re-analysis. Quart. J. Roy. Meteor. Soc., 131, 2961-3012, doi:10.1256/qj.04.176.
Viale, M., and M. N. Nuñez, 2011: Climatology of winter orographic precipitation over the subtropical central Andes and associated synoptic and regional characteristics. J. Hydrometeor., 12, 481-507, doi:10.1175/2010JHM1284.1.

von Mises, R., 1923: Über die variationsbreite einer beobachtungsreihe. Sitzungsber. Berl. Math. Ges., 22, 3-8.

Zecchetto, S., and F. De Biasio, 2007: Sea surface winds over the Mediterranean basin from satellite data (2000-04): Mesoand local-scale features on annual and seasonal time scales. J. Appl. Meteor. Climatol., 46, 814-827, doi:10.1175/ JAM2498.1.

Zhang, K., S. Pan, L. Cao, Y. Wang, Y. Zhao, and W. Zhang, 2014: Spatial distribution and temporal trends in precipitation extremes over the Hengduan Mountains region, China, from 1961 to 2012. Quat. Int., 349, 346-356, doi:10.1016/ j.quaint.2014.04.050. 